\title{
Ether-Based Polyurethane Foam for Vacuum-Assisted Closure (V.A.C.) of Complicated Postoperative Abdominal Wound Dehiscence
}

\author{
AIDA PETCA ${ }^{1,2}$, SILVIUS NEGOITA ${ }^{1,3}$, RAZVAN - COSMIN PETCA ${ }^{1,4 *}$, OANA CALO ${ }^{1}$, \\ RUXANDRA DIANA SINESCU ${ }^{1,5}$ \\ 1 "Carol Davila" University of Medicine and Pharmacy, 8 Eroii Sanitari Blvd., 050474, Bucharest, Romania \\ ${ }^{2}$ Elias University Emergency Hospital, Department of Obstetrics \& Gynecology, 17 Marasti Blvd., 011461, Bucharest, \\ Romania \\ ${ }^{3}$ Elias University Emergency Hospital, Department of Anaesthesiology and Critical Care, 17 Marasti Blvd., 011461, \\ Bucharest, Romania \\ 4 "Prof. Dr. Th. Burghele" Clinical Hospital, Department of Urology, 20 Panduri Str., 050653, Bucharest, Romania \\ ${ }^{5}$ Elias University Emergency Hospital, Department of Plastic Surgery \& Reconstructive Microsurgery, 17 Marasti Blvd., \\ 011461, Bucharest, Romania
}

\begin{abstract}
Background. The macroporous polyurethane ether foam was introduced in the medical field, as early as the 90 ties, for the Vacuum-assisted closure (V.A.C.) of a wound. We describe our experience after treating abdominal wound dehiscence in a group of elderly gynecological patients with NPWT (Negative Pressure Wound Therapy), using ether foam coated with a silver layer. We reviewed elderly patients chart data that underwent abdominal surgery complicated with wound dehiscence treated with $V A C$ for eighteen months. In all patients, the system used was the standard GranuFoam Silver ${ }^{\mathrm{TM}}$ dressing (different extents), which was usually replaced every 48/72 h. A total of 15 consecutive female patients were included. The median age was 67.3 (58-71) years. Duration of VAC treatment was median 14.2 (11-34) days, and we saw an improvement in wound repair but also clearance of S.S.I. on the third day after applying V.A.C. Ulta ${ }^{\mathrm{TM}}$. Definitive secondary closure of the wound was obtained in all patients, as the infection's site clearance. The abdominal VAC treatment with GranuFoam Silver ${ }^{\mathrm{TM}}$ dressing in patients with infected abdominal wound dehiscence is safe and has proper patient compliance. The latest evolution of the silver foam polyether dressing, in conjunction with NPWT therapy, offers a better antimicrobial effect and shorter healing stage.
\end{abstract}

Keywords: polyether foam, silver layer, NPWT, infected wounds, surgical complications

\section{Introduction}

The Polyether-Based Urethane Polymers are the plastic compounds from the polyurethane ether foam. It stands out as an open-cell structure foam, penetrable by fluids, and air. The material's disadvantages are chemical instability, especially on air, if exposed for a significant time, observed as powdering, blemish, alterations of compression qualities. Ether materials were developed recently, almost a decade later than ester foams, aiming to answer the need for smoother, more plastic mats, proving a better reaction to moisture. The ether foams have even surface texture, flat, with a large cell structure.

The open-cell polyurethane ether foam, with a pore size of 400-600 micrometers, is used in the medical field, as early as the 90 ties, for the Vacuum-assisted closure (V.A.C.) of a wound [1,2]. The system utilizes foam shaped according to the size of the injury. An adhesive drape is then fixed over, with an additional four to six cm margin of healthy skin to enclose. Afterward, a trackpad is set over a small gap in the adherent tape. An evacuation tube connects the trackpad to an adjustable vacuum pump and a canister for accumulating discharge fluids [3]. The V.A.C. unit is programmable to generate the recommended level of pressure (intermittent vs. continuous) as high as $200 \mathrm{~mm} \mathrm{Hg}$. Generally, a periodic cycle (five minutes on, two minutes off) is employed, proving the best results.

\footnotetext{
$\overline{\text { *email:drpetca@gmail.com }}$
} 
The suction results in a mechanical decrease of the wound's dimensions, enhances angiogenesis, creates stress within the tissue, determining protein, and matrix molecule synthesis [4].

Nowadays, the method gains larger territories in many surgical fields. In the last decades, the considerable aging population is afflicted with an inflating number of acute and chronic, poorly healing wounds, mainly accountable to the rise in obesity, hypertension, and type 2 diabetes. The pathologic triad is frequently associated with endometrial disturbances in older women, thus explaining the surge in complex operations. Wounds from complex procedures, radiation therapy, severe infections insusceptible to antibiotics, magnifies this medicinal problem. For the time being, wounds have turned into one of the most vivid demands for the health care system worldwide.

Our study aims to describe the results obtained after V.A.C. therapy in a group of elderly gynecological patients. We depict our experience after treating abdominal wound dehiscence with NPWT (Negative Pressure Wound Therapy), along with debridement and infection management. In our lot, we used ether foam coated with a silver layer.

\section{Materials and methods}

\subsection{Patient selection}

For this study, we reviewed elderly patients chart data that underwent abdominal surgery complicated with wound dehiscence. All the patients considered for this study were hospitalized between January 2018 and June 2019 in the Obstetrics and Gynecology Clinic of the Elias Emergency Hospital Bucharest. We reassessed the records for preoperatory status, age, comorbidities (Table 1), current infections, and postoperative evolution. All patients were complicated with postoperative extensive wound dehiscence. The inclusion criteria were full-thickness wound (involving subcutaneous adipose layer down to fascia without extension to muscles or intra-abdominal cavity). The first choice of treatment was debridement and classical wound closure. As wound dehiscence relapsed in all cases, the NPWT device was afterword placed. Surgical site infections were documented, as well as other complications such as seroma, necrosis.

Table 1. Patient characteristics

\begin{tabular}{cc}
\hline & No. of patients $(\boldsymbol{n}=\mathbf{1 5})$ \\
\hline Median age & 67.3 years $(58-71)$ \\
\hline Comorbidities & 12 \\
\hline Hypertension & 7 \\
\hline Diabetes mellitus & 13 \\
\hline Obesity & 7 \\
\hline Previous abdominal surgery & 4 \\
\hline Previous surgical complications & \\
\hline
\end{tabular}

We obtained written informed consent from all patients. As we used a ratified method, there were no ethical oppositions to the study.

\subsection{The methodology of $\mathrm{VAC}^{\circledR}$ application}

The V.A.C. system, in our cases, was applied after surgical debridement and saline solution cleaning of the wound (Figure 1). In every patient, the foam replacement underwent in the operation room under general intravenous anesthesia. The open-cell foam was shaped like a snail's shell to fit the wound's surface accurately (Figure 2). Thus, after the sealing with adhesive drape, the negative pressure becomes evenly distributed over the injury. An opening for the suction tube was made in the sealing drape (Figure $3)$. The tube is then attached to a canister that is connected to a vacuum pump. The vacuum pump uses pressures of 75 to $125 \mathrm{mmHg}$ with a continuous or intermittent vacuum. For all cases, we used silverimpregnated foam sponge, recently introduced, for bacteriocide purposes in patients with colonized wounds [5]. 


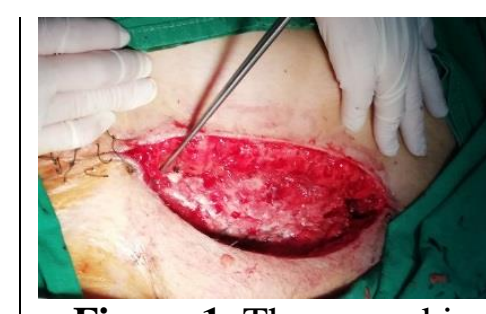

Figure 1. The wound is debrided surgically, saline washed and prepared for V.A.C.

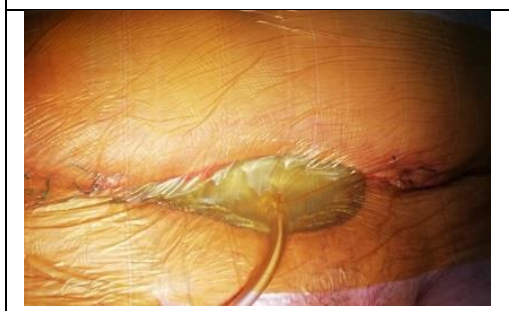

Figure 3. The site is sealed with adhesive drape. An opening for the suction tube is made in the sealing drape

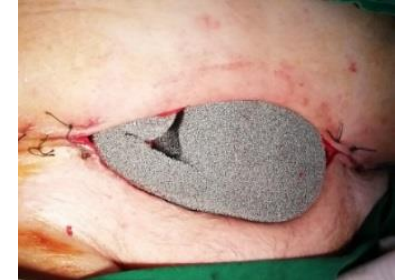

Figure 2. The foam is cut in a snail's shell shape

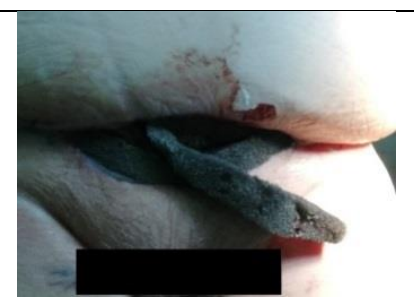

Figure 4. Foam's aspect after three days staying on wound site

The apparatus used was the standard GranuFoam Silver ${ }^{\mathrm{TM}}$ dressing (different extents), which was usually replaced every 48/72 hours (h) (Figure 4). The decision to replace the foam was undertaken based on the quantity of fluid expelled by the wound (whenever the canister became full). Whenever the wound's edges were close enough, we placed some sutures on both ends (Figure 5). The final closing of the injury was achieved gradually, and the stitches were removed after 21 days. At six months postoperatively, all patients presented the completion of the normal healing process (Figure 6).

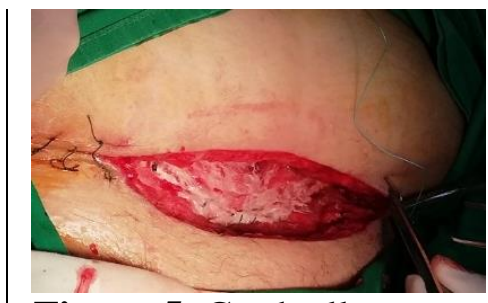

Figure 5. Gradually suture the margins of the injury on both ends

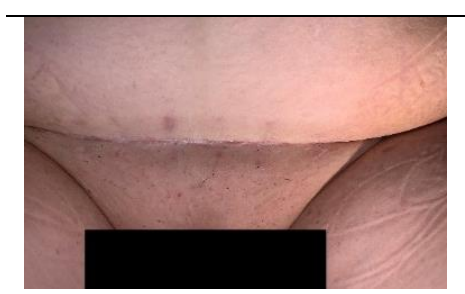

Figure 6. Definitive aspect of one patient six months postoperatively

\section{Results and discussions}

Our study population consisted of 15 female patients who underwent abdominal surgery at Elias Emergency Hospital, with an average age of 67.3 (58-71) years. The type of incision used for the laparotomy was lower Pfannenstiel closed with interrupted sutures. 13 out of the 15 patients were obese, and all of them had other comorbidities. The most frequent, as mentioned in Table 1, were hypertension and diabetes. Cardiovascular and metabolic diseases can delay the healing process and promote bacterial infection. The first choice of treatment for these patients was debridement and classical wound closure. The evolution was unfavorable with wound dehiscence and readmittance, surgical site infections, and other complications mentioned in Table 2. Our approach in wound management was infection treatment with wound debridement and placing the V.A.C. system with GranuFoam Silver ${ }^{\mathrm{TM}}$ dressing. For every 
patient, we used the equipment assembled by 3M K.C.I. Medical Company.

Table 2. Perioperative characteristics

\begin{tabular}{cc}
\hline & No. of patients $(\boldsymbol{n}=\mathbf{1 5})$ \\
\hline Inpatient antibiotics & 15 \\
\hline Surgical site infection & 15 \\
\hline Pluribacterial infection & 5 \\
\hline Seroma & 2 \\
\hline Skin dehiscence & 13 \\
\hline Urinary tract infection & 4 \\
\hline Clostridium difficile & 4 \\
\hline Length of hospital stay & 14.2 days
\end{tabular}

Wound dehiscence is a serious surgical complication that affects a significant number of patients with morbidity and at costs that cannot be ignored. With an increase in mortality, readmission, further surgery, prolonged hospitalization, and impaired psychosocial wellbeing, these are few of the consequences of surgical wound dehiscence [6]. The old methods of management, wet to dry dressing changes, closure by secondary intention in extensive wounds, are now replaced with Negative Pressure Therapy with Vacuum-Assisted Closure (V.A.C) for a quicker healing method [7], proving better results.

In the field of obstetrics and gynecology, abdominal wound dehiscence has an incidence of 3.6 to $29 \%$ [8]. In our clinic, the overall rate of abdominal dehiscence after obstetrical surgery is null, as, for the gynecological one, it reaches roughly $3 \%$ [9].

Our experience in wound repair using the Vac system ultra with GranuFoam Silver ${ }^{\mathrm{TM}}$ dressing showed promising results. Debridement and closure by secondary intention in obese patients were unsuccessful. We saw the need for a better approach, NWTP GranuFoam Silver ${ }^{\mathrm{TM}}$ dressing was favored as a right choice in managing a complex post debridement colonized wounds.

Abdominal surgery per lower Pfannenstiel incision is often chosen in our clinic, proving shorter hospital stay and a faster healing process. Although all patients presented with comorbidities that disrupt the healing process, one cause of wound dehiscence can be attributed to ischemia. The ischemia of vast territories in the superior part of the lower Pfannenstiel incision can be explained by the definitive impairment of the regional capillary venous circulation. Necrosis is a consequence of the upper folding of tegument, fatty tissue, and aponeurosis to create the necessary space for surgical intervention. This necrosis imposes the necessity of large excision to obtain a healthy edge, but also raises the problem of distant margins and tensioned surgical suture. Plus, in obese patients, the abdominal wall folds and often creates a moist space that impairs the healing process and promotes infection.

The negative pressure from the V.A.C. system, which is applied to the dehiscent wound, is said to provide a better environment for healing. The suction effect helps remove the interstitial fluid and contract injury edges to reduce wound size, stimulating angiogenesis and granulation tissue formation, and improving tissue perfusion [5]. We report similar findings. The decrease of tissue edema, promoted by pulling out the extracellular fluid, is one step towards healing and reducing bacterial load. The suction force in the vacuum-assisted closure device is distributed evenly through the foam's pores, thus enhancing granulation tissue formation [10].

Several studies [10-12] found that all wounds exposed to the macroporous polyurethane foam display increased vascularity of the area. They propose an asserting effect of the material itself, instead of the incitement induced by the suction force or mechanical traction on endothelial cells. It is possible that the physics forces are not able to stimulate endothelial cell proliferation directly. Accordingly, the polyurethane foam structure in the vacuum-assisted closure device may be decisive for triggering wound rehabilitation through increased angiogenesis. Other studies [13,14] concluded that the biological interaction between the foam and the wound base has similarities with a nonspecific foreign body-like reaction and results from yet unknown pathways. Recent studies $[15,16]$ brought more light to the matter. 
Understanding the role of the wound/foam assemblage is crucial, as, in clinical practice, different materials are often put between the wound and the foam and may entirely alter the effects on blood vessel formation. Innovations modifying the translation of mechanical and suction forces, as the pore size, firmness of the foam, or the magnitude or waveform of the aspiration, have elucidated the theory and lead to advances in the vacuum-assisted closure device $[15,16]$.

From our, perhaps limited, experience, we advance that foam's qualities are changing, influenced maybe by the migrating fluids, the negative pressure, the condensation, and the infection. After three to five days of staying on the wound site, the foam loses elasticity and compression qualities, changes color, the surface becomes uneven, and the cell structure appears compact, as Figure 5 shows. These findings underline the necessity to change the dressing regularly, dictated not only by the volume of fluids expelled through the tube. Further investigation is beneficial to discover the timeline changes, in peculiar wound site conditions, on polyether foams.

Granulation tissue development is an essential episode in the initial wound restoration, granting a provisional platform for revascularization, cell connection, and inner expansion. The V.A.C. combined with the polyether foam treatment, generates a 2 -fold enhance in granulation tissue forming compared with only an occlusive dressing [2].

Surgical site infection (S.S.I.) presented with isolated E. coli, Klebsiella pneumoniae, Pseudomonas spp from cultures, and in five cases, the simultaneous presence of two bacterial infections. During hospitalization, as showed in Table 2, all patients received antibiotics. A tailored antibiotic therapy corresponding with the results of cultures from the surgical site has the potential to correct patient treatment. Further prospective studies are needed to solve the problem. Throughout their stay, we had four cases complicated with Clostridium difficile, which prolonged their admission, treated with Vancomycine [17]. In all four patients diagnosed with urinary tract infections, antibiotics therapy was instituted in accordance with their uroculture [18]. Management for abdominal wound dehiscence was debridement and applying NPWT with the V.A.C. system. On average, the dressing was changed five times during hospitalization, with no notable skin complications associated with V.A.C. Ulta ${ }^{\mathrm{TM}}$.

During an average stay of 14.2 (11-34) days, we saw an improvement in wound repair but also clearance of S.S.I. on the third day after applying V.A.C. Ulta ${ }^{\mathrm{TM}}$.

The use of the silver foam dressing GranuFoam Silver ${ }^{\mathrm{TM}}$, along with NPWT therapy, offers a better antimicrobial effect and quicker healing phase. Apart from the already proven improvement of vascularization, V.A.C. induces other changes. The foam releases nontoxic levels of silver, has optimal wound conformability, promotes the removal of exudate, thus decreasing bacterial colonization [19].

Another decisive factor in using the V.A.C. System Ultra with GranuFoam Silver ${ }^{\mathrm{TM}}$ dressing is that the foam should be evenly distributed to the entire surface of the wound to reduce the areas where bacteria can proliferate. The bacteriocide effect of the sponge is due to the mechanism of the silver ions in inhibiting cellular respiration, denaturing nucleic acids, and altering cellular membrane permeability and is maximized when there is full coverage of the wound [19].

With bacteria increasing the production of degradative enzymes, managing to disrupt healing and weaken wound tissues, we identified all cases with S.S.I. on readmittance [20]. Although we could not determine if the infection was present before dehiscence, for sure, all patients hospitalized proved surgical site infection by positive cultures. During their stay, all patients received antibiotics as part of infection management, but also NWTP therapy having an adjuvant role in clearing the infection.

We must take into consideration that the costs of wound care seem to be quite high all over the world. American Medicare reported in 2014, approximately 131 billion dollars for nonhealing and infected wounds [21]. The British N.H.S. declared that surgical wounds were the most costly, for about $18.9 \%-$ $21.8 \%$ of total expenditure on wound care [22]. We agree that, although the initial cost of NPWT was higher during treatment, the overall worth was reduced. We explain this fact based on the fewer costs incurred for personnel-related expenses and the shorter duration of hospitalization, treatment, and reduced readmittance. 
The healing phase is quicker than expected when regular dressings are used in a secondary repairing process. NWTP therapy makes it possible to monitor the amount and quality of fluids produced by the wound and to improve patient mobilization, as mobile cans are available for some time. In summary, it demonstrated to be a highly cost-effective way of managing a complex injury.

Because of this, it is used for a wide range of wound types from acute to chronic, and it is suggested as the gold standard for abdominal and sternal dehiscent wounds [23,24].

\section{Conclusions}

We came to the conclusion that NPWT using V.A.C. system ultra with GranuFoam Silver ${ }^{\mathrm{TM}}$ dressing is a safe, effective way to treat infected abdominal wound dehiscence with improvement in the clearance of S.S.I. after applying polyether foam and no notable skin complications.

Although the system is not cheap, and the polyether foam requires frequent replacing, the overall financial burden, as well as the patient's compliance, is acceptable for this kind of medical problems.

The development of the silver foam polyether dressing, in conjunction with NPWT therapy, offers a better antimicrobial effect and shorter healing stage.

\section{References}

1.FLEISCHMANN, W., STRECKER, W., BOMBELLI, M., KINZL, L., Vacuum sealing as treatment of soft tissue damage in open fractures. Unfallchirurg., 96(9), 1993, 488-492.

2.MULLER, G., Vacuum dressing in septic wound treatment. Langenbecks Arch. Chir. Suppl. Kongressbd., 114, 1997, 537-541.

3.COZZA, V., PEPE, G., CINTONI, M., DE MAIO, F., TROPEANO, G., MAGALINI, S., SGANGA, G., et al., Vacuum-assisted closure (VAC@) systems and microbiological isolation of infected wounds. World. J. Emerg. Surg., 13, 2018, 53.

4.ARGENTA, L.C., MORYKWAS, M.J., Vacuum-assisted closure: a new method for wound control and treatment: clinical experience. Ann. Plast. Surg. 38(6), 1997, 563-576;

5.DEFRANZO, A.J., MARKS, M.W., ARGENTA, L.C., GENECOV, D.G., Vacuum-assisted closure for the treatment of degloving injuries. Plast. Reconstr. Surg. 104(7), 1999, 2145-2148.

6.***World Union of Wound Healing Societies (WUWHS) Consensus Document. Closed surgical incision management: understanding the role of NPWT. Wounds International, 2016.

7.BOVILL, E., BANWELL, P.E., TEOT, L., ERIKSSON, E., SONG, C., MAHONEY, J., GUSTAFSSON, R., et al, Topical negative pressure wound therapy: a review of its role and guidelines for its use in the management of acute wounds. Int. Wound J. 5(4), 2008, 511-529.

8.FERRES, M.A., OLIVAREZ, S.A., TRINH, V., DAVIDSON, C., SANGI-HAGHPEYKAR, H., AAGAARD-TILLERY, K.M., Rate of wound complications with enoxaparin use among women at high risk for postpartum thrombosis. Obstet. Gynecol. 117(1), 2011, 119-124.

9.PETCA, A., BORISLAVSCHI, A., DUMITRASCU, M.C., SANDRU, F., GEOARSA, M., PETCA, R.C., Postoperative ileus complicated with incomplete evisceration after hysterectomy for benign pathology. Chirurgia 115(1), 2020, 112-119.

10.SCHERER, S.S., PIETRAMAGGIORI, G., MATHEWS, J.C., PRSA, M.J., HUANG, S., ORGILL, D.P., The mechanism of action of the vacuum-assisted closure device. Plast. Reconstr. Surg. 122(3), 2008, 786-797.

11.WANNER, M.B., SCHWARZL, F., STRUB, B., ZAECH, G.A., PIERER, G. Vacuum-assisted wound closure for cheaper and more comfortable healing of pressure sores: a prospective study. Scand. J. Plast. Reconstr. Surg. Hand Surg. 37(1), 2003, 28-33.

12.KUGLER, N.W., CARVER, T.W., PAUL, J.S., Negative pressure therapy is effective in abdominal incision closure. J. Surg. Res. 203(2), 2016, 491-494.

13.SAXENA, V., HWANG, C.W., HUANG, S., EICHBAUM, Q., INGBER, D., ORGILL, D.P., Vacuum-assisted closure: microdeformations of wounds and cell proliferation. Plast. Reconstr. Surg. 114(5), 2004, 1086-1096. 
14.GREENE, A.K., PUDER, M., ROY, R., ARSENAUlT, D., KWEI, S., MOSES, M.A., ORGILL, D.P., Microdeformational wound therapy: effects on angiogenesis and matrix metalloproteinases in chronic wounds of 3 debilitated patients. Ann. Plast. Surg. 56(4), 2006, 418-422.

15.SINGH, D., CHOPRA, K., SABINO, J., BROWN, E., Practical things you should know about wound healing and vacuum-assisted closure management. Plast. Reconstr. Surg. 145(4), 2020, 839e-854e.

16.LOZANO-BALDERAS, G., RUIZ-VELASCO-SANTACRUZ, A., DÍAZ-ELIZONDO, J.A., GÓMEZ-NAVARRO, J.A., FLORES-VILLALBA, E., Surgical site infection rate drops to 0\% using a vacuum-assisted closure in contaminated/dirty infected laparotomy wounds. Am. Surg. 83(5), 2017, 512514.

17.CALU, V., TOMA, E.A., ENCIU, O., MIRON, A., Clostridium difficile infection and colorectal surgery: is there any risk? Medicina 55(10), 2019, 683.

18.PETCA, R.C., POPESCU, R.I., MARES, C., PETCA, A., MEHEDINTU, C., SANDU, I., MARU, N., Antibiotic resistance profile of common uropathogens implicated in urinary tract infections in Romania. Farmacia 67(6), 2019, 994-1004.

19.GABRIEL, A., HEINRICH, C., SHORES, J.T., BAQAI, W.K., ROGERS, F.R., GUPTA, S., Reducing bacterial bioburden in infected wounds with vacuum assisted closure and a new silver dressing - A pilot study. Wounds 18(9), 2006, 245-255.

20.VAN RAMSHORST, G.H., NIEUWENHUIZEN, J., HOP, W.C., ARENDS, P., BOOM, J., JEEKEL, J., LANGE, J.F., Abdominal wound dehiscence in adults: development and validation of a risk model. World J. Surg. 34(1), 2010, 20-27.

21.NUSSBAUM, S.R., CARTER, M.J., FIFE, C.E., DAVANZO, J., HAUGHT, R., NUSGART, M., CARTWRIGHT, D., An economic evaluation of the impact, cost, and Medicare policy implications of chronic nonhealing wounds. Value Health 21(1), 2018, 27-32.

22.GUEST, J.F., AYOUB, N., MCILWRAITH, T., UCHEGBU, I., GERRISH, A., WEIDLICH, D., VOWDEN, K., et al., Health economic burden that different wound types impose on the U.K.'s National Health Service. Int. Wound J. 14(2), 2017, 322-330.

23.ANGHEL, E.L., KIM, P.J., Negative-pressure wound therapy: a comprehensive review of the evidence. Plast. Reconstr. Surg. 138(3 Suppl), 2016, 129S-137S.

24.APELQVIST, J., WILly, C., FAGERDAHL, A.M., FRACCALVIERI, M., MALMSJÖ, M., PIAGGESI, A., PROBST, A., et al., EWMA Document: Negative pressure wound therapy. J. Wound Care 26(Sup3), 2017, S1-S154.

$\overline{\text { Manuscript received: } 03.05 .2020}$ 